

\section{"Quem Conta um Conto Aumenta um Ponto"; Quem faz uma citação também aumenta um? Intertextualidade e polifonia no texto científico}

\begin{abstract}
RESUMO: Trata-se de uma reflexão sobre a citação no âmbito de abrangência de uma formação discursiva específica, o discurso científico Discute-se a citação no texto científico a partir das contribuições do princípio do dialogismo que atravessa a teoria bakhtiniana da linguagem, problematizando-a como um fenômeno tanto intertextual como polifônico. Considera-se que a citação envolve dimensões intersubjetivas muito além das dimensões técnicas, tratadas de uma perspectiva instrumental em manuais de metodologia da pesquisa.
\end{abstract}

PALAVRAS-CHAVE: intertextualidade, dialogismo, polifonia.

\section{[...] Mas os tivros que em nossa vida entraram} São como a radiação de um corpo negro Apontando para a radiação do universo Porque a frase, o conceito, o enredo, o verso (E sem dúvida, sobretudo o verso) É que pode lançar mundos no mundo Caetano Veloso

\section{O Encontro com Bakhtin e sua Teoria da Linguagem}

Como tão bem o descobriu o dito popular, a resposta é sim, pois quem reconta um conto tanto quanto quem faz uma citação em um texto está criando novos sentidos. Assim, aproveito a deixa para refletir sobre a citação no âmbito de abrangência de uma formação discursiva específica, o discurso científico. Tal exercício implica utilizar as contribuições do princípio do dialogismo que atravessa a teoria bakhtiniana da linguagem, problematizandoa como um fenômeno tanto intertextual como polifônico, na medida em que ela envolve dimensões intersubjetivas muito além
Maria Geralda Gomes Aguiar Doutoranda em Educação Professora Adjunta do Departamento de Saúde da UEFS

maria.geralda.aguiar@terra.com.br 
(1) A este respeito ver a resenha de BORDAS, Miguel Angel Garcia. Augusto Ponzio 1998: “La bachtiniana: il pensiero
di Bachtin e l'ideologia di Bachtin e l'ideologia
contemporanea." Ágere: Revista de Educação e Cultura. Salvador, v. 6, n. 6. p. 189-196. 2002. das dimensões técnicas, tratadas de uma perspectiva meramente instrumental, nos manuais de metodologia da pesquisa.

Por que a teoria da linguagem de Mikhail Bakhtin? Por conta dos vários encontros que tive com alguns dos conceitos e categorias formuladas por este estudioso russo nas suas investigações sobre a linguagem em diversas atividades de disciplinas cursadas no Doutorado em Educação, os quais foram muito significativos, pois me levaram ao estudo do princípio do dialogismo e às noções de intertextualidade e de polifonia.

Encontro com qual dos Bakhtin, seria de perguntar-se? Valho-me da idéia por Todorov (1997), no prefácio de "Estética da criação verbal", de que há vários Bakhtin. Assim, o primeiro encontro foi com o Bakhtin da década de 30 do século passado, marcado por Rabelais e pelas grandes incursões no campo das festas populares, do carnaval, da história do riso e deu-se na disciplina EDC 590 - Currículo: uma possível festa dos loucos. Nessa disciplina, sob o signo do grotesco rabelaisiano, buscou-se operar com o riso na sala de aula, enquanto elemento emancipatório no currículo.

O segundo encontro foi com o Bakhtin fenomenólogo, mediante a leitura, a síntese e a tradução da introdução do livro " $L a$ rivoluzione bachtiniana: il pensiero di Bachtin e lideologia contemporânea" de Augusto Ponzio (1998) ${ }^{1}$. Ponzio defende a tese de que a revolução de Bakthin consiste em haver alterado o ponto de referência da fenomenologia, que já não se coloca mais no horizonte do eu, mas no horizonte do outro. Trata-se de uma mudança que põe em discussão não só o horizonte da filosofia ocidental, mas também o da nossa cultura cuja referência ideológica é a categoria de identidade. O que Bakhtin postula é uma racionalidade fundada na alteridade. Esse encontro também foi significativo porque a tradução, como se sabe, implica recriação e desse modo configura-se como um caso de intertextualidade.

O terceiro encontro foi com o Bakhtin da crítica do formalismo vigente na análise dos textos literários, ao qual se atribui a autoria ou a co-autoria de todo ou de alguns dos capítulos do livro "Marxismo e filosofia da linguagem" (1981), que havia sido creditada a Voloshinov, e deu-se, simultaneamente, nas disciplinas EDC 533 - Linguagem e educação e EDC 703 - O texto e as práticas pedagógicas de leitura. Nesta última, eu e mais alguns colegas apresentamos um seminário sobre intertextualidade e polifonia. 
É, então, do lugar de uma leitora curiosa que me foi possível habitar nos encontros com Bakhtin e alguns dos autores que dialogam com as suas formulações conceituais, abrindo novas perspectivas e trilhas de pesquisa, que elaboro este texto. Um texto ainda prenhe de possibilidades, e, por isso mesmo, marcado pela incompletude, como propunha o próprio Bakhtin.

Para introduzir a questão da intertextualidade e da polifonia, valho-me do próprio conceito de texto apresentado por Bakhtin no livro Marxismo e filosofia da linguagem. Ele compreende o objeto das ciências humanas como um texto em seu sentido lato. Assim, advoga que: "o pensamento do outro e seus múltiplos sentidos só se tornam acessíveis para quem os estuda como uma espécie de texto [...]" (BAKHTIN, 1981, p. 17).

É em razão desse caráter mediado das relações intersubjetivas entre o estudo do homem e de sua vida que os textos sígnicos, de qualquer natureza, são para Bakhtin a única possibilidade de aproximar-se do homem. Bakhtin postula que o homem e suas ações só podem ser objeto de compreensão na experiência sígnica. De modo que é o texto o que possibilita tal compreensão. Onde não há texto, não há objeto de investigação, nem pensamento. O homem se expressa falando, criando textos. Ele é objeto das ciências humanas, como produtor de textos.

Tal conceito coloca-nos em face da necessidade de atentarmos para a dimensão profundamente interativa da linguagem. São os textos criados pelo homem que permitem a reconstrução da língua. É pela via da permuta de textos, de fragmentos de textos que pululam ao redor de um texto (em seu exterior) tomado como foco de estudo e, em seu interior mesmo, que se processa a infindável redistribuição da língua.

Ora, pergunto, quais os fenômenos que permitem a reconstrução da língua da qual Bakhtin fala? São as relações que os textos estabelecem com outros que lhes são exteriores e aquelas que se dão no próprio interior de cada texto que permitem a reconstrução incessante da língua. Uma vez admitida esta hipótese, fundada no princípio do dialogismo, abordado a seguir, torna-se imperativo considerar a presença de textos outros no texto, configurando-o como um intertexto. Sendo todo texto um intertexto, outros textos estarão presentes nele, em graus diversos e de modos mais ou menos reconhecíveis. 


\section{O princípio do dialogismo: sua dimensão interacional e intertextual}

Foi Mikhail Bakhtin quem lançou os alicerces da intertextualidade com o princípio do dialogismo na década de 20 do século passado. O princípio do dialogismo diz respeito à dimensão inerentemente interativa da linguagem oral ou escrita, sua natureza sociohistórica. Dito de outro modo, o dialogismo refere-se ao caráter inerentemente interativo da linguagem, sendo, portanto, inato.

Toda a obra de Bakhtin é atravessada pelo conceito de dialogismo, um conceito que se estrutura a partir da concepção de que a linguagem, em qualquer campo, está impregnada de relações dialógicas. Ele critica as idéias preexistentes sobre a linguagem na medida em que estas postulavam um falante unitário que teria uma relação imediata com "sua unitária e singular linguagem própria". Trata-se de um falante que pensa estar produzindo um significado único na sua fala própria. Tal maneira de pensar a linguagem compreende dois pólos: a linguagem como um sistema, e o indivíduo que fala essa linguagem. Ambos os pólos produzem, no entanto, o que Bakhtin chama de linguagem monológica, pois essa parece vir de uma fonte individual unificada.

O locutor não é um Adão e, por isso, o objeto de seu discurso se torna, inevitavelmente, o ponto onde se encontram as opiniões de interlocutores imediatos (numa conversa ou numa discussão acerca de qualquer acontecimento da vida cotidiana) ou então as visões de mundo, as tendências, as teorias etc. (na esfera da comunicação cultural) (BAKHTIN, 1997, p. 319-320).

No ensaio, "O discurso no romance", Bakhtin concebe o discurso como uma ponte lançada entre sujeitos, socialmente determinados. O dialogismo é apresentado como um princípio abrangente constituído de uma face interacional (diálogo entre interlocutores) e outra intertextual (diálogo entre discursos, o que diz respeito à citação, no sentido mais amplo), que não podem ser dissociadas. Compreende, portanto, não só uma interação face a face, mas a dimensão profundamente interativa da linguagem, o caráter constitutivo da relação eu-outro. 
Bakhtin explica o princípio do dialogismo a partir da idéia de que o enunciado é a unidade da língua:

Toda enunciação, mesmo sob sua forma escrita cristalizada, é uma resposta a alguma coisa é construída como tal. Ela é apenas um elo na cadeia de atos de fala. Toda inscrição prolonga aquelas que a precederam, estabelece uma polêmica com elas, aguarda reações ativas de compreensão, antecipa-se sobre estas etc (BAKHTIN, 1981, p. 106).

Desse modo, toda enunciação é concebida como um elo na cadeia interminável dos atos da fala que precede e sucede a presença de cada homem no mundo. As palavras e as formas de discurso são, portanto, vozes sociais e históricas onde se encontram as opiniões e o senso comum ligados aos acontecimentos da vida cotidiana ou ainda, as visões de mundo, as tendências, as teorias etc, na esfera da troca cultural (BAKHTIN, 1997).

Bakhtin destaca que o caráter da palavra é semi-alheio. As palavras da língua têm um caráter semi-alheio porque estão sempre marcadas pelo outro, tanto o outro que precedeu o locutor nos usos das palavras e as povoou com os seus sentidos, quanto o outro que prefigura o interlocutor para quem o locutor se dirige, presente ou virtual, cuja imagem povoa e também marca a enunciação (SILVEIRA, 1996).

Embora possa existir de três formas: como palavra neutra da língua, como palavra do outro e como palavra minha, a palavra falada situa-se no horizonte conceitual do ouvinte (mesmo que não seja um ouvinte real, mas um ouvinte virtual ou ainda, um ouvinte idealizado, como o 'leitor ideal' de Umberto Eco), isto é, tem como referência o outro. Desse modo, a compreensão de um enunciado é inseparável da resposta (esperada) do ouvinte.

\section{A citação como uma condição - o princípio da intertextualidade}

O princípio da intertextualidade remete a uma característica de todo e qualquer texto: tanto diz respeito a uma propriedade constitutiva do texto (nessa primeira acepção é uma variante da intratextualidade e refere-se às relações que se dão no seu próprio interior), como também ao conjunto das relações que o texto em foco mantém com outros, explícitas e implícitas (transtextualidade). 
(2) Trata-se de uma definição de Júlia Kristeva (apoiada em Bákhtin) que é retomada por Babo.
[...] Qualquer texto se coloca, face aos outros textos, numa relação intertextual, pois define-se como permuta e reagrupamento de outros textos, formando o espaço da citação, do cruzamento ou da negação contestação de textos anteriores [...] (BABO, 1986, p. 3).

E o princípio da intertextualidade, como destaca Babo (1986), que alarga o caráter dialógico de todo enunciado e sublinha, no texto, o seu estatuto de teia, permitindo-nos olhá-lo na sua verticalidade (é espaço do encontro do texto com outros textos) e não na sua linearidade, na medida em que pela intertextualidade o texto define-se como "um mosaico de citações, absorvidas e transformadas"2 (KRISTEVA, citada por BABO, 1986, p. 3).

Pelo princípio da intertextualidade, o texto pode ser concebido nas suas relações com outros textos que o precederam e com os que ainda estão por vir, pode ser concebido também como exercício de escrita que se revela reescrita ou leitura. O percurso de um texto qualquer do autor ao leitor é constituído por um movimento em que se desenvolvem complexas relações na medida em que o texto instiga à leitura, à crítica e à transposição, gerando novas produções que se dão como réplicas e tréplicas em um diálogo que fecunda novos sentidos. Esta é a razão pela qual a intertextualidade é apontada por Beaugrande e Dressler, apud Koch (2001), como um dos critérios de textualidade, pois diz respeito aos modos pelos quais, tanto a produção quanto a recepção de um texto qualquer dependem do conhecimento que alguém (leitor/autor) tenha de outros textos com os quais o texto lido, investigado, de alguma forma, se relaciona. Relações essas, inevitavelmente múltiplas e complexas.

$\mathrm{Na}$ perspectiva de Babo (1986P. 4), o contributo fundamental que a intertextualidade traz a uma nova concepção de textualidade consiste no caráter do texto como tecido fabricado a partir de um entrelaçamento de textos outros, de vários textos, por exemplo, o texto social (que é reestruturado). Conceber o texto como tecido ou tessitura, metáfora barthesiana, independe da noção de intertextualidade, mas a ela remete, como tão apropriadamente o diz Babo, pois implica o seu caráter processual, o seu inacabamento, o ser locus de "fecundações incessantes".

Tratar das relações que o texto estabelece com outros que the são exteriores implica considerar a presença de textos outros no texto, configurando-o como um intertexto. Intertexto e intertextualidade, termos que, muitas vezes, confundem-se, são objeto 
de uma clara distinção no âmbito da análise de discurso, em sua vertente francesa. Usualmente, o termo intertexto é empregado para referir-se a "[...] um conjunto de textos ligados por relações intertextuais $[\ldots]$ ", de modo que designa a reunião de fragmentos citados num corpus; enquanto a intertextualidade é concebida como "[...] o sistema de regras implícitas que subentendem esse intertexto, o modo de citação que é julgado legítimo na formação discursiva da qual depende esse corpus [...]" (MAINGUENEAU, 2000, p. 88). De modo que são diferentes a intertextualidade do discurso científico e a do discurso teológico, não só porque variam de lugar para lugar e de uma época a outra, mas porque obedecem a regras que são válidas dentro do próprio campo, o que constitui e possibilita investigar uma intertextualidade interna, entre textos (discursos) de um mesmo campo discursivo e outra externa, entre textos (discursos) de campos discursivos distintos.

Como argumenta Babo (1986), o texto ao reproduzir ou retomar questões, problemas, idéias já ditas, obtém novos sentidos não só das relações intertextuais com o(s) texto(s) primeiro(s) como também dos seus efeitos de sentido em um novo contexto. É nesse processo de repetição de outros textos, que o novo texto constróise como uma cópia infiel, marcada por falhas, pela subversão do erro, distorcendo sentidos, implicando diferença (isto é, alteridade).

Isto significa que todo texto é um objeto heterogêneo, que revela uma relação radical de seu interior com seu exterior; e, desse exterior, evidentemente, fazem parte outros textos que the dão origem, que o predeterminam, com os quais dialoga, que retoma, a que alude, ou a que se opõe [...] (KOCH, 2001, p. 46).

Um exterior, portanto já habitado tanto por textos aos quais reage, dialogando com eles, na medida em que os retoma, faz alusão ${ }^{3}$ ou a eles se opõe, quanto pelos textos que antecipa. Por exemplo, autores como Jorge Larossa e Robert Darnton falam de um modo todo particular sobre a relação entre leitor e autor, leitor e obra, chamando a atenção para a idéia de que todo leitor é atravessado pelos sentidos que constrói na sua leitura de um texto. É um co-enunciador.

Diz o primeiro:

[...] A experiência de si está constituída, em grande parte pelas narrações. O que somos ou, melhor ainda, o sentido de quem somos, depende das
(3) São considerados três tipos de intertextualidade: a citação, a alusão (reprodução de construções sintáticas) e estilização (reprodução de procedimentos do discurso e do estilo de outrem). 
histórias que contamos e das que contamos a nós mesmos. Em particular, das construções narrativas nas quais cada um de nós é, ao mesmo tempo, o autor, o narrador e o personagem principal. Por outro lado, essas histórias estão construídas em relação às histórias que escutamos, que lemos e que, de alguma maneira, nos dizem respeito na medida em que estamos compelidos a produzir nossa história em relação a elas. Por último, essas histórias pessoais que nos constituem estão produzidas e mediadas no interior de práticas sociais mais ou menos institucionalizadas. Para dizer de forma breve, o sentido de quem somos é análogo à construção e à interpretação de um texto narrativo que, como tal, obtém seu significado tanto das relações de intertextualidade que mantém com outros textos como de seu funcionamento pragmático em um contexto (LARROSA, 1994, p. 4849) (Grifo meu).

Quanto ao segundo, encontra-se esta observação feita por Silva Júnior e Sguissardi (2001, p. 33):

Robert Darnton, em sua obra O beijo de Lamourette, ao referir-se à história do livro, descreve o percurso deste - do autor ao leitor - e as complexas relações que neste movimento se desenvolvem, dando origem a novas produções literárias, diálogos, críticas, réplicas e tréplicas conformadas de novos universos de que o livro é constituinte essencial. Uma rica multiplicidade de atores e eventos passaria a dividir o palco de cena com o texto inicial. Conclui, pois, que a história do livro - desde os sonetos shakespereanos às instruções para montagem de um kit de rádio - é um campo do saber, de sutilezas raras e múltiplas dimensões reveladoras de muito que o próprio livro não fez.

É na citação, como modalidade particular de intertextualidade, que "[...] as interpelações que os textos e as escritas se fazem mutuamente e o posicionamento dos sujeitos" (BABO, 1986, p. 4) vão encontrar condições de possibilidade para o entrelaçamento de textos, demarcando zonas fronteiriças por parentesco (como um tipo de filiação), camaradagem (guardam uma aproximação nas visões de mundo e ou na abordagem científica) ou avizinhamento no mesmo campo discursivo e entre campos discursivos distintos. 


\section{Muito além dos manuais de metodologia da pesquisa: a intertextualidade no texto científico}

Originariamente, a citação constituiu-se como um ato lingüístico de testemunho, mas também como um ato de legitimação que autenticava a veracidade de um discurso. Pelo seu aspecto legitimador, "a citação pode funcionar como a própria performatividade enunciativa. Citar torna-se, assim, o discurso da autoridade" (BABO, 1986, p. 5). A prática da justiça, por exemplo, se faz com base em citações da lei.

E é ainda nessa perspectiva que a citação é descrita em manuais de metodologia da pesquisa ${ }^{4}$, como a menção no texto, de informação colhida de outra fonte, cuja função é a de esclarecimento do tema em discussão, na medida em que lhe cumpre ilustrar ou sustentar o que o(a) autor(a) afirma. Assim, passa-se a idéia de que também o texto científico se elabora com a voz da autoridade, representada pela imagem do(a) cientista que, quando, chamado(a) por meio de uma citação (polifonia explícita), a inscrever-se no texto pelo seu nome ou sua voz, desde já conferiria credibilidade à fala do(a) autor(a). O texto científico escrito é uma produção social que tem características próprias definidas com base nas regras e meios de produção. Caracterizar-se-ia como um tipo de escrita formal. Há elementos estruturais, portanto, que definiriam as suas qualidades fundamentais, dito de outro modo, as suas características próprias, mesmo sob uma forma escrita cristalizada.

Com base nessa definição, são consideradas e definidas em tais manuais duas formas de citação possíveis ao autor ou autora de um texto: a transcrição, concebida como a reprodução literal de um texto de outrem ou parte dele, e a paráfrase, definida como a expressão da idéia de outro(a) autor(a) com palavras próprias, sendo, portanto, elaborada com base em idéias de um autor(a) ou autores(a). Por tratar-se da utilização de palavras alheias no texto próprio, recomenda-se a indicação da fonte, sob pena de plágio.

Pela citação, como condição de intertextualidade, podemos investigar as relações que o texto estabelece com outros que o precederam. Gauthier, Cabral e Santos (1998, p. 10) destacam que, na construção do referencial teórico,

[‥] a busca exaustiva de bibliografia sobre tema e leitura dessas obras contribuem para o pesquisador: evitar a repetição de trabalho realizado
(4) Foram considerados os seguintes manuais: GIL, Antonio Carlos. Relatório da pesquisa. In: Métodos e técnicas de pesquisa social. São Paulo: Atlas, 1999. p. 187-202; CERVO, Amado Luiz: BERVIAN, Pedro Alcino. Como transmitir os conhecimentos adquiridos. In: _. Metodologia científica. 4. ed. São Paulo: Makron Books; SECAF, Victoria. Redação científica: características da linguagem escrita. In: Artigo científico: do desafio á conquista. São Paulo: Reis Editorial, 2000. p. 41-44. 
(5) Babo atua no Departamento de Ciências da Comunicação da Universidade Nova Lisboa, em Portugal. recentemente; atualizar conhecimentos no eixo temático escolhido; modificar, por vezes, o enunciado do problema; ampliar conhecimento sobre novas metodologias que possam ser aplicadas de imediato e identificar especialistas que possam reforçar a nova proposta de investigação.

Muito mais que servir de base, de estrutura, de fornecer um fundante, a pesquisa bibliográfica tem como desafio um diálogo com a teoria. A pesquisa surge do diálogo do(a) pesquisador(a) com a realidade, com outros(a) autores(a) e com os sujeitos da pesquisa. Possibilita contextualizar o problema de pesquisa num campo teórico, inserindo-o na ordem do discurso científico. O pensamento estrutura-se de uma maneira particular articulado com determinadas referências teóricas e não com outras.

Assim os(a) autores(a) são usados porque 'dão o que pensar', porque possibilitam novos modos de pensar, de descobrir novos sentidos, de experimentar novas trilhas de leitura, de pesquisa.

'Teoria', nesses casos, é algo assim como reorganizar uma biblioteca, colocar alguns textos junto a outros, com os quais não têm aparentemente nada a ver, e produzir, assim, um novo efeito de sentido [...] (LARROSA, 1994, p. 35).

O papel do referencial teórico é o de possibilitar o questionamento e a reorientação de formas de pensar e de escrever de determinado campo. Ao invés de ser utilizado como uma malha pré-fabricada, o referencial teórico pode enriquecer, modificar as formas conceituais de um campo por meio da recontextualização de idéias formuladas em outros locais e para outras finalidades.

Aqui trago as contribuições de Maria Augusta Babo ${ }^{5}$ sobre a citação como uma modalidade de transposição de textos na qual a escrita está assentada. A citação é concebida como um recurso no trabalho de escrita, é um dispositivo que possibilita uma abertura para a palavra do outro e o confronto com textos outros. É, portanto, da citação como o espaço do encontro entre um(a) leitor(a) e um texto, um encontro vivido com a palavra do outro e que se dá a conhecer, seja como reprodução literal ou como paráfrase, o que supõe um trabalho de reescrita, que falo aqui.

Ainda bem que entre as regras gerais de citação são consideradas as possibilidades de acréscimos e explicações: que são apresentados entre colchetes []; supressões, indicadas por reticências 
[...]; ênfase ou destaque: grifo ou negrito ou itálico para destacar palavra(s) ou frase(s), devendo-se ter o cuidado de colocar a expressão "grifo nosso" entre parênteses, após a citação.

Muito além dessa dimensão, por assim dizer, técnica, tratada pelos manuais de metodologia da pesquisa, citar é estilhaçar o texto, como nos diz Babo (1986). É fragmentá-lo, dispondo-o em uma outra trama que, de alguma forma, reinventa-o. Por isso mesmo, a citação integral de um texto, implica plágio e constitui crime de falsidade ideológica. Para ela, a citação é "o único 'roubo' consentido ou com sentido: uma repetição comentada, um confronto entre sujeitos". Como ato de leitura, integra-se como operação de corte e de transposição; como ato de escrita, opera uma repetição do já escrito e uma reinserção em outro contexto, o que não deixa de significar, reinscrição na ordem do discurso.

Enquanto leitura a citação aparece, assim, como solicitação do texto à repetição. O que eu cito é aquilo que o texto primeiro me solicita, me convida a retirar e me compele a repetir (BABO, 1986, p. 6).

Citar, tão bem como traduzir, é um processo de transposição de registro, de discurso ou de língua. De modo que a citação remete ao confronto que se operou entre um(a) leitor(a) e um texto. Ela é um produto desse confronto. A citação não fecha o sentido, pelo contrário, abre-o, pois a reprodução de um já escrito, um já dito acarreta uma perturbação do sentido, na medida em que aquilo que já foi escrito ou já foi dito insere-se em um novo texto com(s) outro(s) sentido(s). Para além da repetição de sentido, pela citação, instaura-se, como acentua Babo (1986), o "sentido da repetição", concebido como 'mais valia' do sentido primeiro. Pela citação, fenômeno intertextual, o nome de um outro se inscreve no texto próprio. Assim, a citação faz emergir a alteridade no texto.

$\mathrm{O}$ ato de citar, no entanto, implica uma estratégia dupla no discurso, como ressalta Babo (1986, p. 5): "Se por um lado, a citação anula no texto o sujeito da enunciação que, ao apagar-se, deixa que o 'outro' se inscreva no texto, por outro lado é nessa manha ou disfarce que ele se revela". É, pois, nesse jogo de sentidos, que se abre espaço para a articulação da alteridade.

Para além de uma possível análise da citação como espaço de produção e articulação da alteridade, Babo (1986, p. 4) propõe que se encare a citação, primeiramente, como processo de leitu- 
ra, já que ela é sempre processo de apropriação e de absorção de um texto. Ela cita Compagnon, para quem a primeira forma de citação reside no ato de sublinhar. Nesse sentido, a leitura "é uma forma de adesão ou apropriação do texto". A leitura é marcada por um jogo de apropriação e rejeição que lhe é constitutivo. O ato de ler dá-se como um confronto entre um(a) leitor(a) e um texto. Desse confronto leitor(a)-texto pode resultar que, apropriando-se de um já-dito com o qual corrobora, o(a) leitor(a) deseje co-assiná-lo, perguntando-se, à maneira de Milton Nascimento: "Como não fui eu que fiz?" Pode ocorrer também do(a) leitor(a) recusar ou rejeitar o texto, anulando-o. Em qualquer dos casos, no entanto, produz, muitas vezes, seu(s) comentário(s) à margem. É nesse movimento descrito pelo(a) leitor(a) que sublinhar constitui o ato de ler, mas também o de reescrever. Ler supõe, então, fragmentar um texto, de-compondo-o.

Evidentemente, que a citação, usada como a voz da autoridade, presta-se mais à confirmação de valores consentidos ou consensuais; no entanto, forma uma rede de ressonâncias a deixar resto ou rastro, a criar dissonâncias (BABO, 1986). A citação instala, desse modo, a perversão do sentido ou o espaço que o nega, interdito, no complexo polifônico da intertextualidade. A citação pode, potencialmente, criar mais dissonâncias que ressonâncias, instituir-se como texto paralelo, como texto outro.

\section{Ao modo de uma conclusão}

Creio que a investigação das concepções relacionadas à linguagem, principalmente à interação verbal, ao dialogismo, à repetição e à criação oportuniza uma maior reflexão sobre a citação como expressão do caráter intertextual de todo discurso ou texto e sobre os condicionantes globais da atividade de pesquisa.

Num cenário marcado pela instabilidade, pela perda dos valores e verdades que sustentavam as narrativas da modernidade, o conhecimento define-se mutante. O que aponta não só para a fluidez do conhecimento, mas para a sua provisoriedade, o seu inacabamento. A produção de conhecimento sai do horizonte do eu, a identidade, e toma como referência o outro, como nos propõe Bakhtin.

Todo texto científico é uma produção social que, ao tomar um determinado objeto como foco de interesse, dialoga com ou- 
tros de seu campo discursivo como livros, documentos, artigos de periódicos e, neste sentido, retoma-os ao tempo em que toma uma posição em relação a eles. Além disso, há também polifonia (um movimento) em que parte de um programa de pesquisa (metanarrativa) é retomado e combatido (retomada e oposição) constituindo uma disputa entre concepções de mundo, de ciência, de pesquisa. Essas novas concepções de ciência, verdade, saber, poder propugnam por uma mudança nos pressupostos que guiam a citação, pelo menos, como ela é definida por manuais de metodologia da pesquisa.

Da mesma forma que, no dizer bakhtiniano, ninguém é o Adão bíblico que inaugurará a palavra primeira, ninguém também será a voz da autoridade que colocará o ponto final ou terminal na palavra que constrói um texto, um certo discurso. Antigamente, dizia-se "não se fala mais nisso", "e tenho dito" ou, ainda, "assunto encerrado". Ninguém tem também o poder de dizer algo com a pretensão de que aquela seja a última palavra, não podemos reter ou deter os infinitos efeitos de sentido das palavras ditas, re-ditas, entreditas. A palavra ecoa, ressoa, reverbera, provoca rumores. Mesmo o silêncio que, muitas vezes, faz-se à sua volta é atravessado por múltiplos efeitos de sentido. A primeira condição da intertextualidade é que os textos se dêem inacabados.

Assim, é que se pode conceber a citação expressando-se como um encontro entre textos, que se misturam, desaguando na construção de outro texto. As vozes que compõem a trama discursiva encontram-se e desencontram-se no incessante jogo entre identidade e alteridade.

\footnotetext{
ABSTRACT: This is a reflection about the quotation in the scope of a specific discursive formation, the scientific discourse. We discuss the quotation in the scientific text from the contributions of the dialogism principle. Which goes through the Bakhtin's Language Theory, making it like a phenomenon as intertextual as poliphonic. It has been considered that the quotation involves intersubjective dimensions further the technical dimensions dealing with an instrumental perspective in research methodology manuals.
}

KEY WORDS: intertextuality, dialogism, polyphony. 


\section{Referências}

BABO, Maria Augusta. Da intertextualidade: a citação.Textualidades. v. 3, jun. 1986. www. cecl.pt/rlc/03/rlc03-08.html. Capturado em 27.12.2002.

BAKHTIN, Mikhail. Marxismo e filosofia da linguagem. São Paulo: Hucitec, 1981.

BAKHTIN, Mikhail. Estética da criação verbal. 2. ed. São Paulo: Martins Fontes, 1997.

BORDAS, Miguel Angel Garcia. Augusto Ponzio 1998: La rivoluzione bachtiniana: il pensiero di Bachtin e l'ideologia contemporanea. Ágere: Revista de Educação e Cultura. Salvador, v. 6, n. 6, p. 189-196. 2002.

GAUTHIER, Jacques Henri Maurice; CABRAL, Ivone Evangelista; SANTOS, Iraci dos et al. Pesquisa em enfermagem: novas metodologias aplicadas. Rio de Janeiro: Guanabara Koogan, 1998.

KOCH, Ingedore V. A construção de sentidos no texto: intertextualidade e polifonia. In: O texto e a construção de sentidos. 5. ed. São Paulo: Contexto. 2001. 41-58 p. (Caminhos da lingüística).

LARROSA, Jorge. As tecnologias do eu. In: SILVA, Tomaz Tadeu da. (Org.) O sujeito da educação: estudos foucaultianos. 2. ed. Petrópolis: Vozes, 1994. p. 35-86.

MAINGUENEAU, Dominique. Termos-chave da análise do discurso. Belo Horizonte: Editora da UFMG, 2000. 155 p.

SILVA JÚNIOR, João dos Reis; SGUISSARDI, Valdemar. A educação superior como tema de estudo: eixos para uma agenda a partir do banco de dados Universitas Br. In.:_____. Educação superior: análise e perspectivas de pesquisa. São Paulo: Xamã, 2001. p. 21-43.

SILVEIRA, Rosa Maria B. Olha quem esta falando agora! A escuta das vozes na educação. In: COSTA, Marisa Vorraber (Org.). Caminhos investigativos: novos olhares na pesquisa em educação. Porto Alegre: Mediação, 1996. p. 61-83. 